\title{
Medicalização social (I): 0 excessivo sucesso do epistemicídio moderno na saúde
}

\author{
Charles Dalcanale Tesser ${ }^{1}$
}

TESSER, C. D. Social medicalization (I): the exaggerated success of modern 'epistemicide' in health. Interface Comunic., Saúde, Educ., v.10, n.19, p.61-76, jan/jun 2006.

The process of social medicalization in Brazil is intense and important for the SUS (Unified Healthcare System) - particularly the PSF- and for Collective Health. The purpose of this article is to reflect on this process from a critical and "diagnostic" perspective. To this end, a free outline of Illich's (1975) ideas on the topic is presented, followed by an interpretation of his thoughts from Fleck's (1986) epistemological point of view. Medicalization culturally transforms populations, reducing their ability to face most of the everyday illnesses and pains autonomously. The consequence is an abusive and counterproductive consumption of biomedical services, generating dependency and alienation. According to Fleck, it is the predictable consequence of the fast and forced socialization of the biomedical style of though, which is centered on control and heteronomous actions and interpretations. This mentality was spread to population groups that are not very modern and that are multicultural and of various ethnicities, this being the case of the vast majority of the Brazilian people.

KEY WORDS: drug utilization. knowledge. Family Health Program.

O processo de medicalização social no Brasil é intenso e importante para o SUS (especialmente o PSF) e a Saúde Coletiva. O objetivo deste artigo é refletir sobre tal processo, numa perspectiva crítica e "diagnóstica". Para isso, é apresentada uma síntese livre de idéias de Illich (1975) sobre o tema, seguida de uma interpretação do mesmo a partir da concepção epistemológica de Fleck (1986). A medicalização transforma culturalmente as populações, com um declínio da capacidade de enfrentamento autônomo da maior parte dos adoecimentos e das dores cotidianas. Isso desemboca num consumo abusivo e contraprodutivo dos serviços biomédicos, gerando dependência excessiva e alienação. Vista pelas idéias de Fleck, ela é a previsível conseqüência da socialização forçada e acelerada do estilo de pensamento biomédico (centrado no controle, nas ações e interpretações heterônomas) para contingentes populacionais pouco modernizados, pluriétnicos e multiculturais, como a maioria da população brasileira.

PALAVRAS-CHAVE: uso de medicamentos. conhecimento. Programa Saúde da Família.

\footnotetext{
${ }^{1}$ Departamento de Saúde Pública, Univer sidade Federal de Santa Catarina, SC. <charlestesser@ccs.ufsc.br>
} 


\section{Introdução}

Muito sinteticamente, o processo de medicalização social pode ser visto como a expansão progressiva do campo de intervenção da biomedicina por meio da redefinição de experiências e comportamentos humanos como se fossem problemas médicos.

Illich (1975) analisou e criticou a medicalização social que se acelerava em sua época, ainda mais acirrada no início deste século XXI. I mputou à institucionalização, industrialização e expansão da biomedicina transformações socioculturais e políticas negativas. Sua análise mantém-se atual em vários aspectos, apesar do seu tom agressivo, tendo sido reinterpretada e revalorizada recentemente por Nogueira (2003a).

No Brasil, o recente investimento do SUS na rede básica e no Programa de Saúde da Família (PSF) aumentou o contingente de profissionais de saúde e seu contato com a população, ampliando potencialmente o acesso e o contato das populações com a atenção à saúde biomédica. Este fato torna a questão da medicalização social um tema candente e urgente para a Saúde Coletiva, para a educação permanente dos profissionais de saúde e para sua atuação cotidiana, particularmente para as equipes de PSF (e de toda a rede básica).

O objetivo deste artigo é discutir alguns aspectos do processo de medicalização social ora em vigor no Brasil, como contribuição para uma melhor compreensão da relevância do problema. Isso é particularmente importante em razão do fato de as ações cotidianas de profissionais médicos e equipes de saúde da rede básica serem ativos e intensos agentes desse processo (Tesser, 1999). Numa analogia com o jargão médico, este artigo discutirá um "diagnóstico", mas não entrará na construção de estratégias para o "tratamento", dado seu limite de espaço.

Para realizar este objetivo, será introduzida a visão illicheana da questão, por meio de uma síntese livre da mesma, sob a perspectiva da prática de atenção à saúde na rede básica, a qual induz uma focalização maior no que Illich (1975) chamou de "iatrogênese cultural" desviando, assim, de questões macropolíticas, econômicas e corporativas, as quais não serão abordadas em profundidade. A seguir, uma análise do processo de medicalização social será esboçada a partir das idéias epistemológicas de Ludwik Fleck (1986), previamente introduzidas, de modo a ressituar a visão illicheana e indicar algumas conseqüências práticas da medicalização social para a rede básica do SUS. Isso permitirá delinear, ao final, estratégias de ação e de pesquisa sugeridas para o manejo das questões discutidas.

Parte-se da hipótese de que as idéias epistemológicas de Fleck (1986) relativamente pouco conhecidas e que abordam precisamente as transformações dos saberes por intermédio de extratos sociocognitivos distintos -, podem enriquecer a compreensão do processo de medicalização social, fornecendo relevantes contribuições à Saúde Coletiva.

\section{Sobre a medicalização²}

Há trinta anos, Ivan Illich (1975) lançou a crítica mais contundente até então empreendida contra a medicina moderna, envolvendo seus aspectos culturais, econômicos, sociais e políticos. Mais do que uma crítica à

${ }^{2}$ Esse tópico deriva de parte de um capítulo de meu estudo de mestrado (Tesser, 1999, cap.1). 
3 Illich usa o termo "iatrogenêse" com sentido derivado do uso comum do termo médico "iatrogenia": produção de efeitos deletérios sobrea saúde devidos à ação médica.

${ }^{4}$ Como exemplo, ver Navarro (1975). Adam \& Herzlich (2001), em obra recente, panorâmica e introdutória sobre a sociologia da medicina não dedicam mais que uma pequena nota de rodapé à obra illicheana. medicina, pelo que ficou conhecido, o autor descreveu um movimento cultural cujas dimensões são, hoje, globais.

Sua principal obra, "A expropriação da saúde: nêmesis da medicina", dizia que a medicina institucionalizada transformou-se numa ameaça à saúde. Afirmava que esta ameaça se dá pela difusão de três tipos de iatrogênese $e^{3}$ a iatrogênese clínica, que se constitui nos danos ao indivíduo ocasionados pelo uso da tecnologia médica, diagnóstica e terapêutica. A segunda seria a iatrogênese social, referente ao efeito social danoso do impacto da medicina, que gera uma desarmonia entre o indivíduo e o seu grupo social, resultando em perda de autonomia na ação e no controle do meio, expropriação da saúde enquanto responsabilidade das pessoas e disseminação do papel de doente como comportamento apassivado e dependente da autoridade médica (Nogueira, 2003a). E, por fim, a iatrogênese cultural: a destruição do potencial cultural para lidar autonomamente com boa parte das situações de enfermidade, dor e morte.

Segundo Nogueira (1997, 2003a), esta foi a grande novidade introduzida por Illich: a ampliação do conceito de iatrogênese para abarcar processos difusos e sub-reptícios de medicalização da sociedade. Illich, mergulhado no contexto contracultural da época, foi relativamente pouco considerado pela academia e pela saúde pública ${ }^{4}$, seja pelo radicalismo de sua crítica, afrontoso à subjetividade médica presente nos sanitaristas, seja pela influência marxista na área na sua época.

Como se pode entender a medicalização? Em que ela consiste? Uma breve discussão sobre a dor e o adoecimento ilustra o problema. Para a biomedicina, a dor "é um dos sintomas mais comuns, denunciando lesões orgânicas que determinam o fenômeno reflexo, e, em menor freqüência, exprimindo a origem psicógena. É uma sensação desagradável (...), um fenômeno neurológico reflexo" (Ramos Jr, 1973, p.16). Analogamente, as doenças

Mas para quem a sofre, a dor é bem mais do que isto, assim como as enfermidades são muito mais do que os critérios e saberes médicos. Elas podem ter várias facetas, simultaneamente diferentes, intensas e verdadeiras: um valor intrínseco negativo, fato que designa a experiência da abolição da integridade do indivíduo consigo mesmo e/ ou com seu meio. Assim, a dor ganha caráter trágico, portando certezas excepcionais. De valor incomunicável, e igualmente incontestável, é também inacessível ao termo que a designa clinicamente, não podendo, portanto, ser enquadrada em categoria alguma. Diferentemente de outros males, não admite distinção entre causa nociva e experiência penosa, ficando o indivíduo na solidão de sua experiência pessoal e única (Illich, 1975). 
Paradoxalmente, apesar da incomunicabilidade da dor, a certeza de sua existência (possível) no outro é uma verdade de tipo igualmente excepcional. A percepção da dor no outro denota uma verdade também inquestionável: a certeza de que o outro é capaz desta experiência. Isso acompanha a certeza de que ele é humano (Illich, 1975).

Assim, a dor pode ser chance de envolvimento mais íntimo do doente consigo mesmo, seu meio, sua vida. Tal envolvimento pode ser - e amiúde é - terapêutico; dele pode a pessoa sair mais forte, mais autônoma, mais responsável por si mesma e perante a vida e o sofrimento dos outros. Mas para uma melhor compreensão do problema da dor e do adoecimento, é necessário incluir nessa discussão o contexto sociocultural em que ela ocorre.

A sensação da dor é provocada por mensagens recebidas no cér ebro. No entanto, a experiência da dor, a que Illich reserva o termo sofrimento, depende em qualidade e intensidade de outros fatores, independente da natureza e da intensidade do estímulo nervoso. Linguagem, ansiedade, atenção e interpretação são alguns desses fatores que dão forma à dor e por meio dos quais agem, como determinantes sociais, a ideologia, as estruturas econômicas, as características sociais, as crenças e as concepções sobre o mundo e o homem. Desse modo, é a cultura que orienta o sentido dado ao indivíduo à experiência da dor e do adoecimento. Portanto, uma dor é vivida e se constitui em sofrimento se estiver integrada numa cultura. Justamente pelo fato de a cultura fornecer um quadro que permite organizar o vivenciado, ela é condição indispensável ao desenvolvimento da "arte de sofrer". Fornece elementos para veicular a dor, os sons, as palavras e os gestos que aliviam e permitem a comunicação, o diálogo que liga a vítima ao seu meio. Enfim, a cultura fornece a matriz explicativa, os mitos, o universo simbólico que explica a existência da dor e a ela dá sentido.

Illich localiza o começo da luta ocidental contra a dor em Descartes, que separa o corpo da alma, construindo um modelo em termos de geometria, mecânica e relojoaria semelhante a uma máquina que pode ser reparada por um engenheiro. No fim do século XIX, a dor estava emancipada de todo referencial metafísico. Desde então, ocorreu uma grande virada da medicina ocidental rumo à analgesia, que se insere dentro de uma reavaliação ideológica da dor e do sofrimento, a qual se reflete na cultura e em todas as instituições contemporâneas. Para o autor, a dor e sua eliminação por conta institucional adquiriram lugar central na angústia do nosso tempo. O progresso da nossa civilização torna-se sinônimo de redução de sofrimento, mediante a tentativa de eliminação ou sedação de dores e sintomas e controle dos riscos e doenças crônicas. Assim, a dor, a doença e seus riscos começam a ser vistos primeiro como a condição dos homens a quem a corporação médica não concedeu o benefício de sua caixa de ferramentas (Illich, 1975).

Ao viver em uma sociedade que valoriza a anestesia e a sedação de sintomas, o médico e seu cliente aprendem a abafar a interrogação inerente a qualquer dor ou enfermidade: $O$ que é que não anda bem? Por quanto tempo ainda? Por que é preciso? Por que eu? Qualquer médico sincero sabe que, se ficar completamente surdo à pergunta implícita na lamentação do 
paciente, pode até reconhecer sintomas e fazer diagnósticos corretos, mas não compreenderá nada do sofrimento dele.

Entretanto, o desenvolvimento da faculdade de objetivação da dor e dos sintomas em geral é um dos resultados (perseguidos) da formação científica dos médicos. Seus estudos os incitam a concentrar a atenção nos aspectos classificáveis e manipuláveis da dor e dos outros sintomas. $\mathrm{O}$ ato médico vai, assim, reduzindo-se a uma intervenção mecânica. E a interrogação essencial é transformada em vaga ansiedade que se pode facilmente reduzir ou dissolver por meio de ansiolíticos "eficazes" (Illich, 1975).

Além disso, hoje a profissão médica decide quais as dores ou doenças autênticas, as imaginadas ou simuladas. Os termos com que o médicoprofessor explica aos seus alunos a natureza da dor ganham em precisão objetiva, e os termos de referência subjetiva com os quais os pacientes se esforçam para discernir e dar significado para seus padecimentos esvaziamse e perdem seu poder de comunicação, sendo engolidos e metamorfoseados pelo entendimento e uso médicos. A sociedade reconhece este julgamento profissional e adere a ele. A dor objetiva pode vir a ser sofrimento apenas através do olhar de uma pessoa, mas atualmente é o olhar profissional que mais determina a relação do paciente com a sua experiência.

A institucionalização da dor e dos adoecimentos reflete-se na linguagem e muda o sentido das palavras. A dor corporal é indicada por uma litania de termos que designam o aborrecimento, fadiga, punição, aflição, trabalho penoso, provação, agonia, culpa, vergonha, tortura, medo, ansiedade, tristeza, depressão, opressão, confusão, doença, etc. Mas o sentido em que a palavra "dor" é empregada corretamente numa sala de cirurgia designa alguma coisa que não tinha nome especial para as gerações passadas. A palavra está medicalizada por seu emprego profissional e se reduz à designação da parte da sensação sobre a qual o médico pode afirmar a sua competência e o seu controle.

Para Illich, as culturas tradicionais tornavam o homem responsável por seu comportamento sob o impacto da dor. Tornavam-na suportável e "enfrentável", integrando-a num sistema carregado de sentido. Hoje, a medicalização da linguagem, da resposta à dor e aos sintomas em geral está em vias de determinar condições sociais que paralisam ou diminuem a capacidade de reagir autonomamente frente à dor ou sofrê-la. O tecido de respostas orgânicas, pessoais, emocionais e sociais à dor, propiciado pelas culturas, está em vias de se desfazer (ou já está se desfazendo), "de se transformar em uma demanda geral de gestão técnica das sensações, das experiências e do porvir individuais" (Illich, 1975, p.128).

Em meio medicalizado, a dor perturba e desnorteia a vítima sem que ela tenha outros recursos senão entregar-se ao tratamento médico. A cultura medicalizada deixa o homem desamparado e incompetente, pondo-o nas mãos do trato médico profissional, estranho à compreensão tradicional ou pessoal do doente - às vezes já resquicial - e desagregador das relações entrelaçadoras do homem com sua doença, seu meio, a natureza, seus próximos e com ele mesmo. Assim, a compaixão (fonte de consolo, 
conforto, distração e esperança) e o conhecimento cultural sobre a saúde (tradicional, popular ou de outras medicinas), de gerações anteriores e do entorno social do doente (fonte de tratamento integrado à cultura e à vida do paciente e dos seus), transformam-se em virtudes obsoletas e muitas vezes indesejadas.

Sem matriz cultural ou conhecimento que propiciem outra saída, os pacientes aprendem a conceber sua própria dor ou adoecimento como fato clínico objetivo, que pode ser submetido a tratamento "estandardizado". Cresce, assim, um processo cíclico em que o indivíduo aprende a se ver como consumidor de anestesias, sintomáticos, quimioterápicos e cirurgias.

Por outro lado, e coerentemente, a "saúde" passa a ser encarada como obrigação, em termos de comportamentos prescritos por profissionais da área, screenings periódicos especializados, gestão profissionalizada e, mesmo, quimioterápica dos riscos; uma obsessão do cidadão moderno transformado em consumidor de especialistas, personal trainers, academias e, mais recentemente, "estatinas" ${ }^{5}$, conformando o que Nogueira (2003a) chamou de higiomania moderna, criticada também por Illich nos seus escritos posteriores ao Nêmesis.

Segundo Illich, essa situação chega a ponto de gerar um decréscimo geral no que chamou de índice de boa saúde: a capacidade de manter, intervir e transformar, de forma autônoma e socialmente compartilhada, a própria vida e o meio em que se vive, com vistas a preservar e ou aumentar o grau de "liberdade vivida".

É claro que todo homem tem direito ao conhecimento e à moderna técnica científica e industrial, não só médica, e às informações sobre os benefícios e perigos das drogas e procedimentos usados na medicina. Mas esses progressos, na grande maioria das vezes, só Ihe favorecem a saúde na medida em que alargam sua capacidade e responsabilidade diante de si mesmo e dos que sofrem (Illich, 1975).

Todavia, para um melhor entendimento da crítica illicheana ao domínio das ações heterônomas em saúde-doença, deve-se levar em conta seu conceito de contraprodutividade. A contraprodutividade envolve a idéia de uma ferramenta que passa a produzir efeitos paradoxais, operando contra o objetivo implícito em sua função: o automóvel que produz congestionamentos, a escola que inibe talentos, o hospital que favorece a doença. Isso pode ocorrer por excesso de produção da ferramenta e/ ou por monopolização da sua função.

A contraprodutividade é uma frustração social interna ao uso da ferramenta. Seus custos não podem ser externalizados, nem pode o consumidor recorrer a outra fonte de serviços (outro hospital, por exemplo), porque as condições sociais de profissionalização e do institucionalismo fazem com que todos operem sob a mesma lógica. Ela vem da destruição de certas condições culturais e psicológicas que possibilitam a produção autônoma de valores de uso, por fora dos esquemas mercantis e profissionais que hoje os monopolizam. As pessoas tornaram-se condicionadas a obter em vez de fazer, a comprar em vez de criar: em saúde, não querem mais curar-se, mas serem curadas (Nogueira, 2003a).
${ }^{5}$ Classe de fármacos industrializados usados para reduzir os níveis de lipídios sangüíneos. 
${ }^{6} \mathrm{~A}$ esse respeito, vide Nogueira (2003a).

${ }^{7}$ Para uma apresentação mais detalhada das idéias de Fleck (1986), vide Tesser (2004, cap.1, p.93-107)

${ }^{8}$ A conceituação de estilos de pensamento de Fleck guarda estreita semelhança, coerência e analogia com os paradigmas de Kuhn $(1987,1989)$, embora seja bem mais geral. Os paradigmas podem ser considerados casos particulares de estilos de pensamento, propostos por Kuhn para a atividade científica. Uma comunidade científica seria um caso particular de um coletivo portador de um estilo de pensamento. Discussão e aplicação do conceito de paradigma na medicina encontra-se em Camargo Jr (1992a,b; 1993) Tesser (1999), Nogueira (2003b).
A partir de certo limiar de expansão da produção heterônoma, o equilíbrio sinérgico entre as ações de saúde autônomas (realizadas pelo indivíduo ou seus pares no seu meio social autóctone) e as ações heterônomas (realizadas e controladas por agentes profissionais institucionalizados) é rompido internamente, ao passo que a contraprodutividade começa a crescer e a expandir-se, retroalimentando positivamente a produção de ações heterônomas. A conseqüente expansão da produção heterônoma gera mais contraprodutividade, e ambas, por sua vez, geram a ilusão da necessidade de mais ação heterônoma para corrigir os efeitos indesejáveis e paradoxais produzidos. Perde-se, assim, a ajuda mútua, a sinergia positiva entre as ações heterônomas e autônomas, criando-se um círculo vicioso contraprodutivo.

No caso da atenção à saúde, a ação especializada, em vez de promover a autonomia do doente, para que este possa necessitar menos de novas ações heterônomas e melhor usufruir de ações eventuais ou necessárias, destrói a autonomia, reivindicando submissão, alimentando a dependência e a compulsão ao consumo, gerando mais demanda por atenção heterônoma, comprometendo, por fim, a sua própria efetividade e eficácia geral.

\section{As idéias de Fleck}

O enfoque illicheano, apesar de suas valiosas pistas para a abordagem do tema (aqui não discutidas ${ }^{6}$ ), parece não ter mobilizado suficientemente a atenção da Saúde Coletiva, dos gestores do SUS e do ensino médico nas últimas décadas.

Para iluminar a questão da medicalização de forma distinta, pode-se pensá-la com base nas idéias epistemológicas de Ludwik Fleck (1986) sobre os estilos e coletivos de pensamento e o metabolismo do saber que ocorre por meio dos círculos sociocognitivos do coletivo geral de um estilo de pensamento ${ }^{7}$.

Um estilo de pensamento é um conjunto entrelaçado de tradição, valores, crenças metafísicas, modelos abstratos, representações simbólicas, métodos e exemplos de procedimentos, aprendidos por semelhança e iniciação ao modo tradicional (extracientífico), que os membros de um coletivo de pensamento compartilham para determinada ação, projeto ou interesse específico ${ }^{8}$.

Os estilos de pensamento, ao mesmo tempo em que coagem e direcionam o pensamento, a percepção e a cognição, têm uma função pedagógica essencial ao proporcionar um corpo de verdades, valores e métodos prontos que viabilizam a introdução dos novatos no estilo do pensamento. Além disso, exercem uma função sociocognitiva e psicológica de permitir a coalizão dos participantes em torno de certa realização intelectual, tecnológica, cultural etc. Para Fleck, os estilos de pensamento são unidades de análise fundamentais para a compreensão da construção e transformação do saber e sintetizam em si fatores de ordem sociopsicológica, cognitiva, histórica, filosófica e cultural.

Segundo o autor, algo como um "metabolismo" psico-sócio-cognitivo do saber desenrola-se entre os círculos sociocognitivos de um coletivo de pensamento portador de um estilo. Toda a base de um saber especializado 
deriva do senso comum, da cultura geral, dos extratos exotéricos de qualquer estilo de pensamento, que fornece o senso de confiança, as concepções gerais de mundo e universo, a estabilidade emocional das certezas evidentes por si sós. Esse saber e algumas partes dele são reconstruídos, elaborados, sofisticados e transformados pelos círculos progressivamente mais esotéricos (especializados) de um estilo de pensamento, escrutinados pelos interesses, métodos, valores e técnicas desenvolvidos por esses círculos, ganhando nova dimensão, muitas vezes gerando novos saberes e concepções, permitindo descobertas, especializações, eficácias, novas idéias e tecnologias. Estas permitirão novas práticas sociais que podem, agora, fazer o caminho de volta ao mundo exotérico (social geral) e o influenciar.

Nesse caminho de volta, os saberes de novo se transformam, ficando mais simples, dogmáticos e esquemáticos. Afastado do centro esotérico em direção à periferia exotérica, o saber fica fortemente dominado por um grafismo emotivo que confere a ele segurança subjetiva do evidente. $\mathrm{O}$ saber exotérico caracteriza-se pela omissão dos detal hes e uma valorização apodídica que consiste no simples aceitar ou rechaçar certos pontos de vista.

Uma vez estabelecido firmemente no saber exotérico e popular até que se torne uma coerção do pensamento, o saber retorna ao especialista como um fundo cultural, perceptivo e cognitivo, como aquilo que é pura evidência, que não se precisa mais provar nem se pode mais questionar aquilo que não se pode pensar de outro jeito. Desta maneira, fecha-se o círculo da dependência intracoletiva do saber.

No caso da biomedicina, discutida por Fleck, os círculos exotéricos são os pacientes dessa medicina, uns mais outros menos exotéricos, conforme seu grau de afinidade e de socialização no saber biomédico. Os círculos mais esotéricos, os núcleos centrais destes círculos, são os grupos de cientistas "de ponta" ou de excelência, que se debruçam sobre determinados problemas, temas ou investigações. Os médicos clínicos estão localizados na periferia dos círculos esotéricos, em extratos intermediários, já que iniciados no estilo de pensamento e habilitados como praticantes portanto, social e estilisticamente especializados - mas não tão especializados na produção de saber como os cientistas.

A transformação do saber pelos círculos eso-exotéricos de um coletivo de pensamento, como descrita por Fleck no caso da ciência, permite alguma compreensão da dinâmica de transformações intensas por que passa a população brasileira, hoje, no seu contato com a biomedicina, ou seja, enquanto círculo bem exotérico desse saber/prática.

A conformação do saber médico, como um saber estruturado num estilo de pensamento superespecializado, sofisticado, elaborado e em pleno desenvolvimento, orienta a percepção, a cognição e a abordagem do profissional na prevenção dos adoecimentos, na promoção da saúde e no tratamento de indivíduos e de coletividades. Proporciona alguns tipos de ação e afasta outros. Porta eficácias e certos tipos de explicação, bem como implica limites e cegueiras comuns à maioria dos extratos do coletivo biomédico, particularmente os esotéricos (por causa de sua maior imersão 
na perspectiva estilística). Como discuti em outros momentos (Tesser, 2004, 1999; Tesser \& Luz, 2002), isso tem importância na medicalização social cotidiana e em vários dilemas éticos, técnicos, terapêuticos e relacionais na prática biomédica da atenção à saúde.

\section{Fleck e a medicalização}

Passados os radicalismos da contracultura (de Illich) e certas crenças ou simplificações do marxismo anterior à queda do muro de Berlim, podem-se considerar os efeitos construtivos e, para alguns, desejáveis da medicalização social. É possível, também, analisar os fundamentos epistemológicos da mesma e considerar sua irreversibilidade relativa, enquanto construção cultural em acelerado andamento no Brasil - já que a maioria da população, moradora em centros urbanos, nos últimos anos, tem algum contato com a biomedicina por meio do SUS. É nesse sentido que ensaio uma pequena análise nas linhas que se seguem.

Inicialmente, é preciso esclarecer e resgatar certos pressupostos e crenças iluministas, racionalistas e modernas sobre a atuação histórica e social da ciência, para que se possa considerar a medicalização social no seu contexto desejável, como um suposto projeto moderno de emancipação social ou, ao menos, de mudança cultural em saúde-doença, centrada no saber científico.

A ciência nasceu e se diferenciou de todos os outros saberes querendo ser superior, única e exclusiva. Conseguiu atingir seus objetivos em grande medida, embora parcialmente. A veracidade é, hoje, monopólio da ciência na área da saúde, no ocidente.

“O privilégio epistemológico da ciência moderna é produto de um epistemicídio" (Santos, 2000, p.242) de outras formas de saber e fazer entrelaçadas com valores, tecnologias, modos de vida, culturas e sociedades diversas das vigentes na sociedade moderna (e pós-moderna) européia ou, recentemente, norte-americana. Assim, a homogeneização dos saberes em saúde-doença, centrada no saber científico, nas suas tecnologias correlatas (industrializadas), no pensamento moderno e sua noção de progresso, é saudada como uma vitória, uma grande realização, para os defensores da superioridade científica.

Todavia, essa homogeneização dos saberes culturais em saúde, se é fortemente promovida pela mídia, pelo contato com a biomedicina e pela globalização, dá-se de forma assíncrona e desarmônica em relação aos processos de socialização social e econômica no terceiro-mundo e no Brasil. Além disso, a cultura européia (e norte-americana), de modo geral, não se expande em um vazio cultural ou sociotécnico, ao contrário. Encontra, combate, domina, destrói, transforma e constrói por sobre uma população heterogênea, com cultura mestiça sulista pobre (por oposição ao norte rico), pluriétnica, multicultural e, em boa medida, sincrética, com saberes e fazeres mais ou menos próprios e diversos.

A socialização ampla do estilo de pensamento biomédico em nosso país só pode se dar na periferia exotérica do seu coletivo, onde a simplificação, o pragmatismo e a transformação dos saberes são inevitáveis e sofrem influência dos demais estilos de pensamento, valores culturais, 
representações, religiões e crenças populares do Brasil.

As pessoas não-européias (latino-americanas, africanas, asiáticas e mestiças), imersas em redes sociotécnicas ${ }^{9}$ distintas, participantes de círculos exotéricos (quando não esotéricos) de coletivos de pensamentos diversos, portam valores e representações com pouca semelhança ou afinidade com o estilo de pensamento biomédico.

Assim, os cidadãos pobres brasileiros, mal-alfabetizados, em princípio, carregam um imaginário de crenças, representações, valores e cosmologias em saúde-doença muito mais distintos do estilo de pensamento biomédico do que os círculos exotéricos da biomedicina, por exemplo, na Europa onde a alfabetização, a escolarização e a inserção cultural e social do saber científico são mais velhas e mais capilarmente difundidas na população. Inevitavelmente, no Brasil, o contato exotérico com tal estilo implica maiores metamorfoses de sentido, maior simplificação e maior grau e variedade de "anomias vivenciais" nas interpretações e nos tratamentos médicos dos adoecimentos, bem como relevantes conflitos de várias naturezas, além de uma maior dificuldade comunicacional entre o curandeiro biomédico e os doentes (ou usuários), com discrepâncias de valores e dissensos simbólicos, geralmente antiterapêuticos e pouco promotores de saúde ou autonomia.

Mediante o modelo de Fleck, torna-se compreensível a perspectiva popular que pode parecer absurda a uma primeira vista. Por derivar de outros círculos exotéricos, socializados em meios socioculturais nãointelectuais nem cientificizados, fascinados pela versão midiática milagrosa da propaganda científica, pressionados pela globalização, precariedade da moradia e do emprego, violência, pobreza e pelo desemprego, a maioria dos brasileiros não poderia mesmo agir de outro modo. Suplica por uma vaga nos serviços, aumenta as filas dos pacientes do SUS, para todos e quaisquer adoecimentos, transtornos e queixas.

Ensinados a esquecer, menosprezar e desqualificar todos os cabedais de saber es autóctones para interpretação e manuseio dos adoecimentos e sofrimentos vividos; ensinados a buscar na causa biológica e no tratamento quimioterápico/cirúrgico a solução de todos os males; ensinados a esperar do especialista e dos exames complementares a elucidação e a cura de tudo, os doentes agem coerentemente.

A biomedicina, por sua vez, ensina essas lições aos doentes no dia-a-dia da clínica (Tesser, 1999), por intermédio de um dos instrumentos mais poderosos em qualquer situação ou tradição: o exemplo. Os biomédicos, eles mesmos, praticam esses ensinamentos, conforme seu estilo de pensamento ensina, e assim geram para si um excesso de demanda que encobre, por um lado, seus próprios limites e, por outro, desvia a atenção de médicos e doentes das influências complexas sociopsicológicas, ambientais, espirituais e econômicas sobre a vida e o adoecimento das pessoas.

Os otimistas do desenvolvimento econômico talvez argumentassem que, com mais empregos, mais saneamento, mais educação, mais escolarização, essas mazelas do subdesenvolvimento seriam equacionadas. Todavia, as redes sociotécnicas da biomedicina, de ordem mercadológica e comercial, os 
valores e as culturas remanescentes do processo colonialista não parecem indicar tanto otimismo e esperança a curto ou médio prazo. Em todo o caso, enquanto o milagre moderno (ou pós-moderno) não chega, cabe-nos a consideração das realidades presentes e suas tendências.

Do ponto de vista do projeto político da ciência, a medicalização social não só é desejável como pode ser considerada uma vitória da modernidade e da biociência. Nessa perspectiva, é o sucesso do projeto político-cultural e epistemológico da socialização geral do saber científico pelo mundo, que não pode ocorrer senão por meio do contato dos seus próprios círculos intermediários e exotéricos com as constelações culturais e de saberes, de vários tipos, dos doentes e das populações, ainda plurais no Brasil. Devido às peculiaridades político-epistemológicas da biomedicina e ao seu sucesso na luta pelo "monopólio epistemológico" institucional, este contato, obtido no mundo ocidental e expandido com a globalização, é dominador, desqualificador e epistemicida, como se mimetizasse, em alta velocidade e com muito mais contraprodutividade, a socialização que a biociência viveu em séculos passados na Europa.

Trata-se, portanto, de um processo colossal de epistemicídio progressivo de saberes e estilos de pensamento em saúde-doença, mais ou menos estruturados, e de práticas diluídas nas culturas, populações e subculturas, importantes para o manejo autônomo dos problemas em saúde-doença, agora em rápida transformação ou extinção parcial. Um processo cuja conseqüência é a homogeneização - pautada pela heteronomia - dos saberes/práticas em saúde-doença (e modos de vida em geral), criticada por Feyerabend (1991), particularmente quanto ao seu pressuposto fundador e justificador, transformado em mito na modernidade: a idéia disseminada da superioridade epistemológica total da biociência e sua biomedicina.

Outro aspecto a ser ressaltado é que o estilo de pensamento dessa medicina produz e porta um conhecimento basicamente de terceira pessoa (para usar um jargão epistemológico atual), cuja tradição reserva toda competência epistemológica e tecnológica para os pólos esotéricos de si mesma; ou seja, ela é calcada na inter pretação e intervenção heterônomas especializadas e superespecializadas, no controle heterônomo.

De modo que é coerente com a socialização generalizada dessa tradição o atual desenrolar sociocultural exotérico do saber/fazer em saúde-doença, o qual se caracteriza por uma progressiva incompetência epistemológica cíclica por parte das pessoas e mesmo, em certo grau, dos médicos, a periferia exotérica dos círculos esotéricos. O pólo exotérico transforma-se progressivamente em consumidor de tecnologias biomédicas industrializadas, o intermediário (o profissional clínico) em consumidor de saberes e prescritor dessas tecnologias ou comportamentos.

Paradoxalmente, o progresso emancipador da ciência parece ter, em parte, saído pela culatra, ao menos para os que acreditavam ou acreditam nessa promessa ou potencialidade emancipadora do processo sociocognitivo científico.

A ciência, ao transformar-se em mito, ao centralizar em si, enquanto instituição, toda competência e excelência epistemológica, esvaziando ou extirpando, progressivamente, esta competência da vida dos leigos, 
participa do reverso de seu suposto projeto emancipador: a construção da incompetência epistemológica moderna em saúde-doença de todas as pessoas, por meio da medicalização social, do excesso de sucesso da socialização do saber biocientífico e das tecnologias científicas nessa área.

Por outro lado, ao se levarem em conta as redes sociotécnicas que se organizaram e estão envolvidas na construção e sustentação da biomedicina, pode-se observar o lado exitoso de um projeto sociocognitivo e político, agora sem crenças ingênuas nem críticas raivosas ou excessivamente militantes. Nesse sentido, um projeto de desenvolvimento de relações sociais e práticas de saberes em saúde-doença baseados essencialmente nas relações de consumo (no sentido econômico, capitalista, do termo) pode ser vislumbrado.

Nesse aspecto, está envolvida a aceleração da socialização de práticas científicas, centradas no controle heterônomo, o maior valor ao redor do qual se organiza a ciência, segundo Lacey (1998). Um valor eminentemente político, mas também social e psicológico, e curiosamente não-cognitivo ${ }^{10}$. O que parecia radicalmente agressivo e pessimista, a construção da incompetência epistemológica moderna, torna-se, agora, instrumento de socialização acelerada, de complexificação e extensão das redes sociotécnicas dos insumos e das tecnologias biomédicas, de inclusão e geração de consumidores que nem dinheiro para o consumo têm - mas o SUS financiará grande parte do tratamento. Dependência e incompetência são requisitos bem-vindos para aumentar a extensão da rede biomédica (científica e industrial) de controle dos riscos e das doenças, ao passo que toda a contraprodutividade será debitada na conta alheia, atribuída às mazelas da "falta de educação" dos pacientes.

Isso é compreensível mediante a visão de Latour (2000a) sobre a separação moderna entre teoria e prática: enquanto no alto da limpidez das teorias tudo vai bem, no mundo independente da prática, vai se construindo uma vida mais tensa, controlada e homogênea, mais pobre e difícil, para a maioria da população, em que as redes sociotécnicas do mercado e da biomedicina (supondo esta em algum grau separada daquele) se expandem por todo país, medicalizando-o.

O poder estende-se e centraliza-se (Latour, 2000b), a irresponsabilidade cresce até não poder ser mais reconhecida, até tornar-se hegemônica e dominar o tônus ético-moral dessa tradição moderna recente de curandeiros oficiais. As conseqüências, mazelas, os efeitos, estragos e reparos serão feitos por outros, de outro tempo, outra disciplina, outra especialidade. O meio entre a "natureza biológica das doenças" (saber científico sobre uma suposta natureza eterna sem história) e a sociedade (cultura), o lugar não-moderno onde tudo ocorre, é o meio tenso em que se dá a medicalização social aqui revisitada.

Segundo Hösle (apud Müller, 1996), três são os postulados fundamentais da modernidade: o infinitismo científico (a criação de metanecessidades a serem satisfeitas por uma mediação técnica cada vez mais complexa e custosa, na dependência crescente de aparelhos e tecnologia científica); o princípio do verum factum (só o que é tecnicamente feito pelo homem é verdadeiro, o que proclama a
${ }^{10}$ Isso vale a pena ser ressaltado porque grande parte da epistemologia louva e admira a ciência por seus valores cognitivos (como, por exemplo, adequação empírica, consistência, simplicidade, fecundidade, poder explicativo, verdade), considerando todos os outros tipos de valores por ventura encontrados ou intervenientes na produção do conhecimento e no próprio saber como males ou partes inevitáveis do contexto social e histórico da ciência, que não pertenceriam ao seu conteúdo. 
construtividade essencial da ciência - e a destrutividade dela para o que não é ela mesma); e o programa cartesiano de transformação da qualidade em quantidade, corporificado na hegemonia das metodologias das ciências naturais na biomedicina. Esses postulados dão uma idéia da conotação exitosa do processo de medicalização social, o qual é plenamente coerente com o desdobramento sociocultural exotérico dos mesmos na área da saúde. Bem como deixam entrever as conexões recíprocas entre ciência, técnica e capitalismo, configurando redes sociotécnicas relativamente pouco exploradas e analisadas, entre nós, na área da saúde.

\section{Conseqüências para a atenção básica do SUS}

O desfecho prático do processo de medicalização social, precocemente descrito por Illich e iluminado pelas idéias de Fleck, mostra que gripes, resfriados, lutos, pequenas contusões e ferimentos, tristezas, crises de relacionamento sentimental, familiar e conjugal, dores ocasionais, recorrentes ou crônicas, mortes e nascimentos, crises existenciais etc., passam a ser vertiginosamente medicalizados, carentes de interpretação e prescrição médica ou de especialista similar.

Assim, um dos subprodutos evidentes da medicalização social, visível para todos os que trabalham ou têm contato com o dia-a-dia da atenção à saúde nos serviços públicos, é a bola de neve crescente e infindável da demanda espontânea por atenção médica para todos os tipos de problemas, queixas, dores e incômodos. Fenômeno complexo, de múltiplos e amplos determinantes, que, cada vez mais, tem exigido espaços de acolhimento "resolutivo", de atenção médica, administração e triagem das filas. Isso faz com que o tema seja candente na prática, no cotidiano dos serviços do SUS, na rede básica e nas equipes de PSF.

Tal fenômeno associa-se a várias epidemias de adoecimentos etiquetados no saber exotérico, que avassalam os serviços públicos: dores incontáveis, depressões, tendinites, pânicos, hipertensões, sinusites, viroses, gripes, alergias dos mais variados tipos etc. Esses adoecimentos são simultaneamente reais e artificiais, já que a popularização dos diagnósticos força uma homogeneização precoce das histórias clínicas e dos diagnósticos sobre elas produzidos, ao mesmo tempo em que as condições de vida e trabalho impostas pela globalização pressionam e degradam a situação de saúde da maioria da população.

Isso significa uma infinidade de novos problemas de saúde, criando uma demanda crescente e praticamente impossível de se resolver por meio das tecnologias habituais da atenção biomédica (quimioterapia e cirurgias), como tem sido feito, senão medicalizando tudo cada vez mais, gerando aumento de demanda no futuro próximo, aumentando a contraprodutividade.

Por fim, pode-se considerar que a análise precedente sugere uma dupla estratégia diagnóstica da situação, ao mesmo tempo assistencial e de pesquisa, inspirada em Boaventura Santos (2004): considerar a biomedicina (e sua socialização) indispensável para o mundo contemporâneo e, simultaneamente, inadequada, incompleta e perigosa, particularmente se levados em conta os processos de medicalização, 
iatrogenia cultural e contraprodutividade envolvidos no seu exercício contemporâneo institucional.

Indispensável porque já está legitimada social e culturalmente nas populações e estruturas sociais do ocidente e detém poder social inédito como única referência epistemológica. Além disso, porque já não se sabe mais o que fazer sem ela para muitas situações e provavelmente tenha contribuído sobremaneira, de muitas formas, para o tratamento de vários adoecimentos, particularmente os "graves".

Essa medicina é inadequada porque centrada no controle heterônomo, vinculado com redes e forças de poder social e econômico mercantis, e que solapam ou dificultam a autonomia, alimentando a dependência das pessoas, medicalizando-as. Por outro lado, seu estilo de pensamento é reducionista e mecanicista em excesso, pouco sensível a muitos adoecimentos de difícil enquadramento, para os quais não proporciona interpretação coerente que forneça sentido para a vivência do adoecimento e para uma terapêutica efetiva, acessível, sustentável e que reforce a autonomia (Tesser, 1999).

Pode-se, assim, propor a tese da indispensabilidade e inadequação ou incompletude da biomedicina e sua socialização ampla. Abre-se, com isso, o desafio de se tentar algum grau de intervenção ou direcionamento no processo de medicalização, tanto na assistência individual e microcoletiva de pequena escala - PSF, rede básica - como no SUS em geral.

Isso demanda produção de conhecimento para a compreensão do processo e construção de projetos de investigação e ação. Demanda, também, clareza sobre o poder da ação medicalizante da atenção básica, que agora pode entrar nos domicílios atendidos pelas equipes do PSF. E, particularmente, supõe conhecimento sobre o modus operandi da atuação dos médicos e seus saberes sobre a cultura em saúde dos usuários, sempre em algum grau reconstruída a cada interação usuário-serviço ou médicopaciente.

Nesse sentido, a nova proximidade e interação permitida pelo PSF é uma faca de dois gumes: pode ser uma chance para a reorientação da medicalização e reconstrução da autonomia, mas também, e facilmente, pode constituir-se em uma nova força medicalizadora poderosa.

A construção de sabedorias para o manejo dessa complexa questão no dia-a-dia dos serviços é um desafio que fica aqui apenas registrado. Pensando nele, para finalizar, esboço um balizamento que sugere três frentes de atuação e pesquisa para o "tratamento" do problema. A primeira é a crítica, a ressignificação e reconstrução do saber e das práticas típicas da biomedicina, sua reforma por dentro. Desafio para a formação e a educação permanente em saúde, especialmente o ensino médico.

A segunda é a abordagem, o resgate e o estudo das medicinas nãocientíficas, mais ou menos complexas e/ou tradicionais, como potenciais parceiras a atenuar, iluminar e relativizar a inadequação da medicina científica. Elas podem ser futuros e valiosos parceiros da tradição biomédica, da Saúde Coletiva e do SUS no cuidado à saúde. Particularmente, por hipótese, quanto à promoção da saúde, à evitação da medicalização excessiva e da contraprodutividade específica da biomedicina ${ }^{11}$.
11 Vide Luz (1997), OMS (2002), Ernst (2001), Tesser (2004, cap. 2). Para propostas de abordagem nãoepistemicida de sistemas médicos complexos, vide Tesser (2004, cap.3), e de racionalidades médicas, vide Luz (1996, 1997). 
A terceira frente envolve a reconstrução da relação do saber biocientífico com a vida cotidiana e com os saberes vários disseminados na sociedade, os quais não devem ser apenas desqualificados, como tem ocorrido em grande medida. As posturas biomédicas, em regra, são dominadas pelo viés da heteronomia total e pelo preconceito cientificista que só valoriza o saber superesotérico científico, desqualificando todo o resto. É preciso superar a tendência controlista, da clínica biomédica e saúde pública, de pensar os sujeitos e grupos sociais apenas pelo lado da sua submissão e "aderência".

Essas frentes de trabalho constituem desafios sugeridos para se lidar com o problema da medicalização social, carentes de melhor desenvolvimento, tanto para o trabalho assistencial na rede básica e PSF, quanto institucional, nos vários níveis do SUS - para o que se espera contribuir em breve.

\section{Referências}

ADAM, P.; HERZLICH, C. Sociologia da doença e da medicina. Bauru: EDUSC, 2001.

CAMARGO JR., K. R. O conceito de paradigma em Kuhn: aplicação na epistemologia do saber médico. Rio de Janeiro: Instituto de Medicina Social, Universidade Estadual do Rio de Janeiro, 1992a. Mimeografado.

CAMARGO JR., K. R. Paradigmas, ciência e saber médico. Rio de Janeiro: Instituto de Medicina Social, Universidade Estadual do Rio de Janeiro, 1992b (Série Estudos em Saúde Coletiva, n.6).

CAMARGO JR., K. R. Racionalidades médicas: a medicina ocidental contemporânea. Rio de Janeiro: Instituto de Medicina Social, Universidade Estadual do Rio de Janeiro, 1993 (Série Estudos em Saúde Coletiva, n.65).

ERNS, E. (Ed.) Medicina complementar: uma avaliação objetiva. São Paulo: Manole, 2001.

FLECK, L. La génesis y el desarrollo de un hecho científico. Madrid: Alianza Editorial, 1986.

FEYERABEND, P. K. Adeus à razão. Lisboa: Edições 70, 1991.

ILLICH, I. A expropriação da saúde: nêmesis da medicina. 4.ed. São Paulo: Nova Fronteira, 1975.

KUHN, T.S. A estrutura das revoluções científicas. São Paulo: Perspectiva, 1987.

KUHN, T.S. A tensão essencial. Lisboa: Edições 70, 1989.

LACEY, H. Valores e atividade científica. São Paulo: Discurso Editorial, 1998 (Coleção Filosofia da Ciência \& Epistemologia).

LATOUR, B. Jamais fomos modernos: ensaios de antropologia simétrica. Rio de Janeiro: Ed. 34, 2000a (Coleção trans).

LATOUR, B. Ciência em ação: como seguir cientistas e engenheiros sociedade afora. São Paulo: Ed. UNESP, 2000b.

LUZ, M.T. Racionalidades médicas e terapêuticas alternativas. Rio de Janeiro: Instituto de Medicina Social, Universidade Estadual do Rio de Janeiro, 1996 (Série Estudos em Saúde Coletiva, 62).

LUZ, M. T. Cultura contemporânea e medicinas alternativas: novos paradigmas em saúde no fim do século XX. Physis - Rev. Saúde Coletiva, v.7, n.1, p.13-43, 1997.

MÜLLER, M. L. Vittorio Hösle: uma filosofia da crise ecológica. Cad. Hist. Filosofia Cienc., v.6, n.2, p.9-62, 1996. 
TESSER, C. D.

NAVARRO, E. S. The industrialization of fetishism or the fetishism of industrialization: a critique of Ivan Illich. Int. J. Health Services, v.5, n.3, p.351-71, 1975.

NOGUEIRA, R. P. Risco, confiança e satisfação: a contingência da saúde na modernidade. 1997. Projeto de Tese (Doutorado) - Instituto de Medicina Social, Universidade Estadual do Rio de Janeiro, Rio de Janeiro.

NOGUEIRA, R. P. A saúde pelo avesso. Natal: Seminare, 2003a.

NOGUEIRA, M. I. Entre a conversão e o ecletismo: de como médicos brasileiros tornam-se "chineses". 2003b. Tese (Doutorado em Saúde Coletiva) - Instituto de Medicina Social, Universidade Estadual do Rio de Janeiro, Rio de Janeiro.

ORGANIZAÇÃO MUNDIAL DE SAÚDE - OMS. Estratégia de la OMS sobre medicina tradicional 2002-2005. Genebra, 2002.

RAMOS JR., J. Semiotécnica da observação clínica. 3.ed. São Paulo: Sarvier, 1973.

SANTOS, B. S. A crítica da razão indolente: contra o desperdício da experiência. 2.ed. São Paulo: Cortez, 2000.

SANTOS, B. S. Do pós-moderno ao pós-colonial. E para além de um e outro. Coimbra, 2004. Disponível em <http://www.ces.fe.uc.pt/misc/Do_pos-moderno_ao_pos-colonial.pdf>. Acesso em: 05 jul. 2005.

TESSER, C. D. A biomedicina e a crise da atenção à saúde: um ensaio sobre a desmedicalização. 1999. Dissertação (Mestrado em Saúde Coletiva) - Faculdade de Ciências Médicas, Universidade Estadual de Campinas, Campinas.

TESSER, C. D.; LUZ, M. T. Uma introdução às contribuições da epistemologia contemporânea à medicina. Cienc. Saúde Coletiva, v.7, n.2, p.363-72, 2002.

TESSER, C. D. Epistemologia contemporânea e saúde: a luta pela verdade e as práticas terapêuticas. 2004. Tese (Doutorado) - Faculdade de Ciências Médicas, Universidade Estadual de Campinas, Campinas.

TESSER, C. D. Medicalización social (I): el exceso del éxito del epistemicidio moderno en la salud. Interface - Comunic., Saúde, Educ., v.10, n.19, p.61-76, jan/jun 2006.

El proceso de medicalización social en Brasil es intenso e importante para el Sistema Único de Salud (SUS), en especial para el PSF (Programa Salud de la Familia) y la Salud Colectiva. El objetivo de este artículo es reflexionar acerca de tal proceso, desde una perspectiva crítica y "diagnóstica". Por lo tanto, se presenta una síntesis libre de las ideas de Illich (1975) acerca del tema, y después una interpretación del mismo a partir de la concepción epistemológica de Fleck (1986). La medicalización transforma culturalmente a las poblaciones, trayendo una disminución de la capacidad de enfrentamiento autónomo de la mayoría de las enfermedades (trastornos) y dolores cotidianos. Eso acarrea un consumo abusivo y contraproductivo de los servicios médicos, generando dependencia excesiva y alienación. Vista a través de las ideas de Fleck, la medicalización es la previsible consecuencia de socialización forzada y acelerada del estilo de pensamiento biomédico (centrado en el control, en las acciones e interpretaciones heterónomas) para contingentes poblacionales poco modernizados, multiétnicos y multiculturales, como la mayoría de la población brasileña.

PALABRAS CLAVE: utilización de medicamentos. conocimiento. Programa Salud de la Familia.

Recebido em: 22/11/05. Aprovado em: 25/05/06 